\title{
A Comprehensive Prediction Model of Rock Strength and Its Application on Classifying the Rock During the Drilling
}

\author{
Lu Yang ${ }^{1}$, Yinan Guo ${ }^{1,}$, Cancan Liu ${ }^{2}$ \\ ${ }^{1}$ School of information and Control Engineering, China University of Mining and Technology, Xuzhou, China \\ ${ }^{2}$ School of Mines, Key Laboratory of Deep Coal Resource Mining, Ministry of Education of China, China University of Mining and \\ Technology, Xuzhou, China
}

\author{
Email address: \\ yanglu@cumt.edu.cn (Lu Yang), TB18020012B0@cumt.edu.cn (Yinan Guo), liucancan@cumt.edu.cn (Cancan Liu) \\ ${ }^{*}$ Corresponding author
}

\section{To cite this article:}

Lu Yang, Yinan Guo, Cancan Liu. A Comprehensive Prediction Model of Rock Strength and Its Application on Classifying the Rock During the Drilling. Advances in Applied Sciences. Vol. 5, No. 3, 2020, pp. 82-87. doi: 10.11648/j.aas.20200503.15

Received: September 10, 2020; Accepted: September 21, 2020; Published: September 29, 2020

\begin{abstract}
Geological data plays an indispensable role in mining coal safely and efficiently. Traditional rock core method not only have some defects of high labor intensity, high cost and slow speed, but also difficultly got the rock of the weak interlayer. Based on this, parameter-based identification method of the rock characteristics during the drilling operation is a hot research topic. In this paper, a comprehensive prediction model was established to predict the rock Uniaxial Compressive Strength (UCS). Besides, the prediction results of the comprehensive prediction method, multiple linear regression model, and Mechanical Specific Energy (MSE) model were compared. Furthermore, the K-means clustering method is used to classify the rock formation based on the measured drilling parameters. The result indicates that torque work is significantly correlated with the UCS of rock. The comprehensive method has the best prediction result, and the prediction error of rock's UCS is within 5MPa. The prediction results of rock classification are different from the actual results, but from the perspective of rock strength, this classification method is better. The rapid identification method of rock formation based on MWD provides a reference for the roadway support scheme and parameter design, and is an important part of the intelligent development of coal mines.
\end{abstract}

Keywords: Measurement While Drilling, Parameters While Drilling, Rock Classification, Support Parameter, Uniaxial Compressive Strength

\section{Introduction}

Geological data plays an essential role in mining coal safely and efficiently. To obtain the accurate geological information on the roof, rich studies had been done. The commonly-used rock core method not only wasted time and money, but also difficultly got the rock of the weak interlayer. Tian, et al. [1] analyzed the rock breaking mechanism and the parameters acquisition method during the drilling process. However, the rock core method cannot meet the needs of coal-mining because the characteristic of the rock in the roof may change over time. To address the issue, video image technology was introduced to sample the image from the borehole by $3 \mathrm{D}$ laser and recognize the characteristics of rock rapidly [2]. Zhao [3] employed three-dimensional borehole resistivity imaging approach to detect the rock stratum of a goaf in coal mine. By compared with the rock core method, image-based method cannot obtain the strength information of the rocks. Based on this, parameter-based identification method of the rock characteristics during the drilling operation is still a hot research topic.

To recognize the characteristics of the rocks according to the dynamic response of various parameters during the drilling process was of great significance [4]. Vardhan, et al $[5,6]$ discovered that the relationship between the measured pressure and the strength of rocks. Yasar [7] proved that the mechanical specific energy (MSE) exhibited a strong linear correlation with the unconfined compressive strength (UCS). Rodgers, et al [8] found that the ratio of torque to the drilling speed had a direct relationship with MSE. The models for evaluating MSE are shown in Table 1 [9-14].

Until now, many scholars had studied the classification methods of rock stratum based on various parameters that 
obtained from the drilling operation. Liu, et al. [15] detected the formation of rock stratum in terms of the drilling and rotation pressure of bolters. Rostami, et al. [16] analyzed the vibration response of the drill bit passing through the rock fissure during the drilling. Liu, et al. [17] employed the finite element simulation to explore the relationship among energy response, the vibration of drilling pipe, penetration rate, and pressure. Furthermore, the coal-rock interface was identified by the combination of minimum enclosing balls classifier with support vector machines (SVM) in terms of the penetration rate and the vibration by Song, et al. [18] and Liu, et al. [19]. Kernel Fisher was also employed to classify the rock from coal with well logs [20]. However, the existing prediction models of rock strength were complex and the single classification method provided the limited accuracy for detecting the formation of rock stratum. To handle the drawback, a comprehensive approach that predicts UCS at first, and then classifies the rocks from coal by the combination of the silhouette coefficient and $\mathrm{K}$-means clustering is proposed.

Table 1. The models for MSE.

\begin{tabular}{|c|c|c|}
\hline & $\begin{array}{l}\text { The author for } \\
\text { the models }\end{array}$ & The models \\
\hline 1 & Teale (1965) & $M S E=\frac{F}{A}+\frac{120 \pi N M}{A V}$ \\
\hline 2 & $\begin{array}{l}\text { Dupriest and } \\
\text { Koederitz (2005) }\end{array}$ & $M S E=0.35\left(\frac{F}{A}+\frac{120 \pi N M}{A V}\right)$ \\
\hline 3 & $\begin{array}{l}\text { Cherif and Bits } \\
\text { (2012) }\end{array}$ & $M S E=E_{m}\left(\frac{4 F}{\pi D^{2}}+\frac{480 N M}{\pi D^{2} V}\right)$ \\
\hline 4 & Chen et al. (2016) & $M S E=\frac{36 M}{D F e^{-\mu \gamma b}}$ \\
\hline 5 & Al-Sudani (2017) & $M S E=\frac{1}{V} \sqrt{\frac{F(120 \pi N)^{2} M}{g_{c}\left(\frac{D}{12}\right)^{2}}}$ \\
\hline 6 & $\begin{array}{l}\text { Wang et al. } \\
(2018)\end{array}$ & $M S E=\frac{2 \pi N M-\pi \mu N F\left(2 r-\frac{L_{1}^{2}+L_{2}^{2}+L_{3}^{2}}{L_{1}+L_{2}+L_{3}}\right)}{\pi r^{2} V}$ \\
\hline
\end{tabular}

\section{The Prediction Model of Uniaxial Compressive Strength}

Assuming that the UCS of a rock is predicted by multiple linear regression, the MSE method and the synthesis method based on the measured parameters during the drilling process. Multiple linear regression as a most commonly-used method in dependent variable prediction, can be summarized as:

$$
R_{1}=\lambda_{1} V+\lambda_{2} N+\lambda_{3} M+\lambda_{4} F+\varepsilon
$$

Where $R_{1}$ denotes the predicted UCS. $\lambda_{1}, \lambda_{2}, \lambda_{3}$, and $\lambda_{4}$ represent the coefficients of the model to be determined. $\varepsilon$ is a constant term and $F$ is the thrust; $V$ is the penetration rate. $M$ is the torque and $N$ is the rotary speed. $\mu$ is the friction coefficient between the drill bit and the rock stratum and $\mu=0.21$ [21].

Let $\mathrm{W}_{\mathrm{F}}, \mathrm{W}_{\mathrm{M}}$, and $\mathrm{W}_{\mathrm{f}}$ represent the work done by the thrust, the torque, and the friction of the drill bit, respectively. The MSE has a direct relationship with the strength of the rock.

$$
M S E=W_{F}+W_{M}-W_{f}
$$

Where

$$
\begin{gathered}
W_{F}=\frac{F}{\pi r^{2}} \\
W_{M}=\frac{M N}{30 r^{2} V} \\
W_{f}=\frac{\mu F N}{60 r V}
\end{gathered}
$$

Then, the UCS of a rock, expressed by $R_{2}$, is obtained.

$$
R_{2}=\lambda M S E+\varepsilon
$$

Where $r$ is the radius of the borehole and $\lambda$ represents the coefficient of the model to be determined. Based on this, a comprehensive prediction model of UCS of rocks is proposed, with purpose of predicting UCS denoted as $R_{3}$.

$$
R_{3}=\lambda_{1} \frac{F}{\pi r^{2}}+\lambda_{2} \frac{M N}{30 r^{2} V}+\lambda_{3} \frac{\mu F N}{60 r V}+\varepsilon
$$

\section{The Classification Method of Rock Formation}

The measured data that obtained from the sensors of displacement, penetration rate, pressure, torque and rotary speed during the drilling process form the input array, denoted as $\left(t_{1}, F_{1}, M_{1}, N_{1}, V_{1}\right),\left(t_{2}, F_{2}, M_{2}, N_{2}, V_{2}\right), \ldots,\left(t_{n}, F_{n}\right.$, $\left.M_{n}, N_{n}, V_{n}\right)$. The corresponding UCS is predicted through the above three models. Assuming that the array corresponding to the $i$-th rock formation is $\left[\left(t_{a}, R_{a}\right),\left(t_{a}+1, R_{a}+1\right), \ldots,\left(t_{b}, R_{\mathrm{b}}\right)\right]$. The UCS of this rock formation is gotten as follows.

$$
R_{c i}=\frac{1}{b-a+1} \sum_{i=a}^{b} R_{i}
$$

It can be seen from Equation (8) that ta and tb represent the moment when the bit drills into and out of the i-th layer, respectively. In order to identify the rock strength accurately, it is necessary to automatically determine the thickness of each kind of rock based on the drilling parameters. The silhouette coefficients is employed to determine the optimal number of classifications for the sample data $\left[\left(t_{1}, R_{1}\right),\left(t_{2}\right.\right.$, $\left.\left.R_{2}\right), \ldots,\left(t_{\mathrm{b}}, R_{\mathrm{b}}\right)\right]$. The silhouette coefficient that is closer to 1 means the better classification performance. This silhouette coefficient is calculated by Equation (9).

$$
S\left(R_{i}\right)=\frac{b\left(R_{i}\right)-a\left(R_{i}\right)}{\max \left\{a\left(R_{i}\right), b\left(R_{i}\right)\right\}}
$$


Where $a\left(R_{i}\right)$ represents the average distance from sample $R_{i}$ to other samples in the same cluster. $b\left(R_{i}\right)$ denotes the average distance of $R_{i}$ to all points in the nearest cluster. Following that, the sampling data are classified by K-means clustering method according to the optimal number of classifications.

\section{Case Verification}

\subsection{Analysis of the Prediction Accuracy of Uniaxial Compressive Strength}

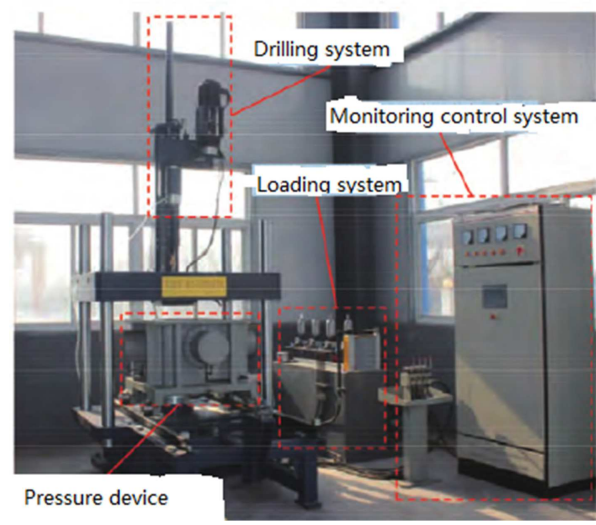

(a) Multi-functional rock drilling system.

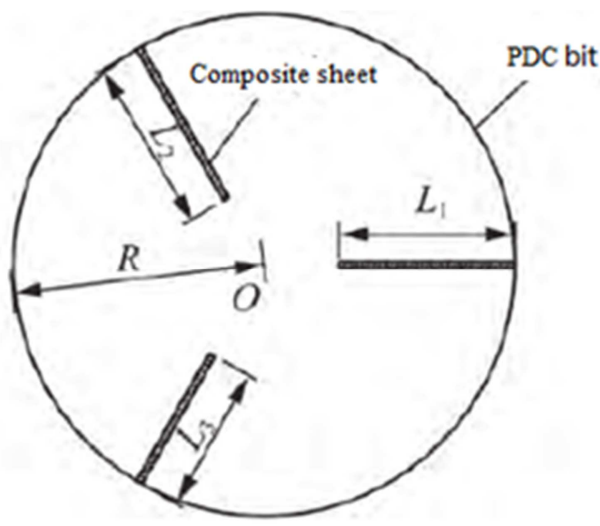

(b) Diagram of drill bit cutting edge.

Figure 1. The drilling device [14].

The experimental data in the literature [14] is employed to verify the validity of the above-mentioned prediction model for UCS of rocks. The drilling device is shown in Figure 1.

8 mortar specimens and 8 sandstone specimens that have different strength are labelled by J1-J28 and S1-S8, respectively. The experimental data is divided into two groups. The data listed in Table 1 is employed to train the coefficients of Equations (1), (6) and (7) by fitting analysis and the data shown in Table 2 is used to predict UCS of the rock through the models.

Table 2. The experimental data [14].

\begin{tabular}{|c|c|c|c|c|c|c|}
\hline Specimen types & Number & $V(\mathbf{m m} / \mathbf{m i n})$ & $N(\mathbf{r} / \mathrm{min})$ & $M(\mathbf{N} \cdot \mathbf{m})$ & $F(\mathrm{kN})$ & UCS (MPa) \\
\hline \multirow{4}{*}{ M5 } & $\mathrm{J} 1$ & 148.46 & 50 & 18.92 & 0.02 & 1.90 \\
\hline & $\mathrm{J} 2$ & 177.89 & 100 & 14.43 & 0.01 & 2.00 \\
\hline & $\mathrm{J} 3$ & 185.07 & 100 & 12.98 & 0.01 & 1.94 \\
\hline & $\mathrm{J} 4$ & 174.69 & 100 & 13.99 & 0.01 & 1.99 \\
\hline \multirow[b]{2}{*}{ M7.5 } & $\mathrm{J} 5$ & 124.8 & 50 & 17.01 & 0.03 & 2.37 \\
\hline & J6 & 87.94 & 100 & 7.30 & 0.02 & 2.58 \\
\hline \multirow{4}{*}{ M10 } & J9 & 81.52 & 50 & 17.05 & 0.03 & 6.70 \\
\hline & $\mathrm{J} 10$ & 103.09 & 100 & 12.22 & 0.02 & 7.20 \\
\hline & $\mathrm{J} 11$ & 112.75 & 100 & 10.13 & 0.03 & 6.24 \\
\hline & $\mathrm{J} 12$ & 130.77 & 100 & 14.67 & 0.03 & 6.99 \\
\hline \multirow{3}{*}{ M15 } & $\mathrm{J} 13$ & 83.85 & 50 & 28.77 & 2.79 & 10.23 \\
\hline & $\mathrm{J} 14$ & 83.95 & 100 & 16.42 & 2.66 & 10.05 \\
\hline & $\mathrm{J} 16$ & 118.08 & 100 & 21.44 & 2.07 & 10.60 \\
\hline \multirow{3}{*}{ M20 } & $\mathrm{J} 17$ & 83.91 & 50 & 45.43 & 2.23 & 23.54 \\
\hline & $\mathrm{J} 18$ & 83.65 & 100 & 29.89 & 2.33 & 30.81 \\
\hline & J19 & 111.42 & 100 & 35.88 & 3.01 & 22.43 \\
\hline \multirow{3}{*}{ M25 } & $\mathrm{J} 21$ & 83.46 & 50 & 43.66 & 3.44 & 21.66 \\
\hline & $\mathrm{J} 22$ & 84.23 & 100 & 26.15 & 1.20 & 27.80 \\
\hline & $\mathrm{J} 23$ & 137.82 & 100 & 38.30 & 3.16 & 22.22 \\
\hline \multirow{3}{*}{ M30 } & $\mathrm{J} 25$ & 84.64 & 50 & 41.49 & 0.85 & 27.71 \\
\hline & $\mathrm{J} 26$ & 82.88 & 100 & 25.99 & 0.51 & 35.21 \\
\hline & $\mathrm{J} 27$ & 137.84 & 100 & 31.36 & 1.49 & 22.73 \\
\hline \multirow{4}{*}{ sandstone } & $\mathrm{S} 1$ & 79.97 & 50 & 103.08 & 5.59 & 58.09 \\
\hline & S3 & 84.07 & 150 & 40.69 & 2.65 & 59.95 \\
\hline & S5 & 84.90 & 250 & 28.00 & 2.15 & 61.91 \\
\hline & S6 & 84.41 & 300 & 23.78 & 2.05 & 60.88 \\
\hline
\end{tabular}


Table 3. The experimental data for verifying the UCS [14].

\begin{tabular}{llllll}
\hline S Specimen types & Specimen number & $\boldsymbol{V}(\mathbf{m m} / \mathbf{m i n})$ & $\boldsymbol{N}(\mathbf{r} / \mathbf{m i n})$ & $\boldsymbol{M}(\mathbf{N} \cdot \mathbf{m})$ & $\boldsymbol{F}(\mathbf{k N})$ \\
\hline M7.5 & J8 & 138.95 & 100 & 8.38 & 0.05 \\
M20 & J20 & 137.76 & 100 & 43.29 & 3.22 \\
M25 & J24 & 112.42 & 100 & 24.25 & 2.41 \\
M30 & J28 & 114.25 & 100 & 30.32 & 22.05 \\
sandstone & S2 & 82.21 & 100 & 53.10 & 28.94 \\
sandstone & S4 & 84.09 & 200 & 62.60 & 32.28 \\
\hline
\end{tabular}

From the experimental data in Table 1, the UCS prediction models based on multiple regression, MSE model and comprehensive prediction method are constructed as follows.

$$
\begin{gathered}
R_{1}=-8.47596 * 10^{9} * V+240453 * N+845054 \\
* M-1849.23 * F-8144460 \\
R^{2}=0.9383 \\
R_{2}=0.5109 * M S E-4 * 10^{6} \\
R^{2}=0.9746 \\
R_{3}=5.3556 * \frac{F}{\pi r^{2}}+0.520923 * \frac{M N}{30 r^{2} V} \\
-0.70105 * \frac{\mu F N}{60 r V}-4794050 \\
R^{2}=0.9857
\end{gathered}
$$

It can be seen from the predicted UCS shown in Figure 2 that the multiple linear regression model has the largest prediction error, and the comprehensive method has the best prediction result.

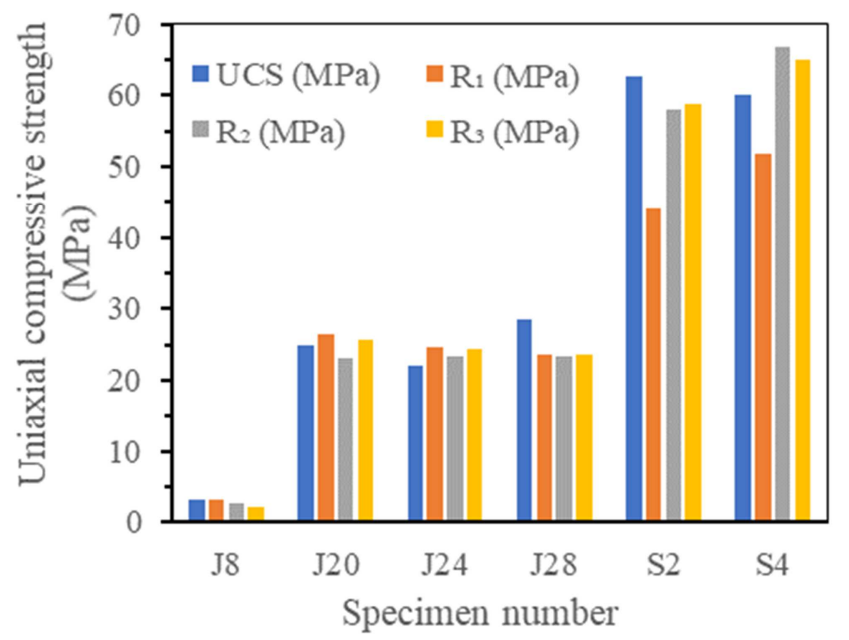

Figure 2. The prediction results of UCS.

\subsection{Analysis of the Classification Performance of the Rock in a Roof}

It is assumed that 36 experimental data of $\mathrm{J} 1 \sim \mathrm{S} 8$ are collected during the drilling process and the predicted UCS are obtained by the comprehensive method. After determining the most appropriate number of classification by the silhouette coefficients, these specimens are classified through K-means clustering method. The silhouette coefficients shown in Figure 3 indicate that the classification performance is best as the number of the clusters are 4 .

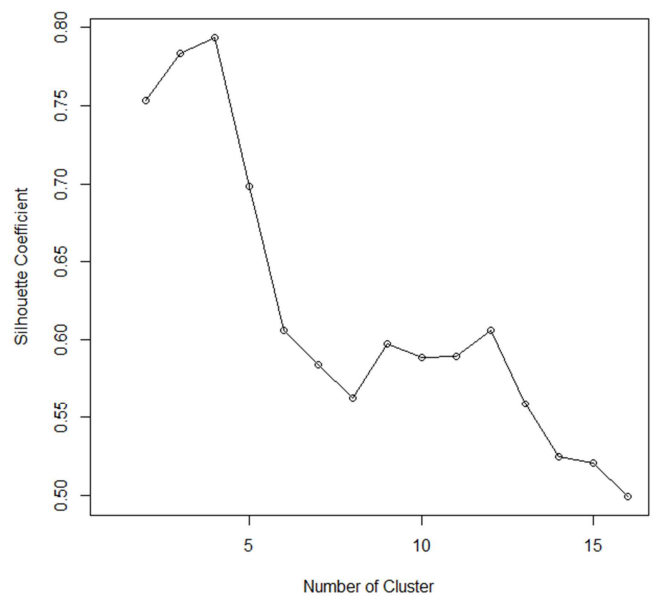

Figure 3. The silhouette coefficients under different numbers of classification.

We see from the classification results shown in Figure 4 that the UCS of four kinds of rocks are mainly concentrated in $0 \sim 5 \mathrm{MPa}, 5 \sim 11 \mathrm{MPa}, 20 \sim 30 \mathrm{MPa}$ and $50 \sim 60 \mathrm{MPa}$, which is consistent with the actual test piece strength. According to the Equation (7), the UCS of these rocks are $3.35 \mathrm{MPa}, 8.97$ $\mathrm{MPa}, 24.34 \mathrm{MPa}$, and 58.76 $\mathrm{MPa}$, respectively.

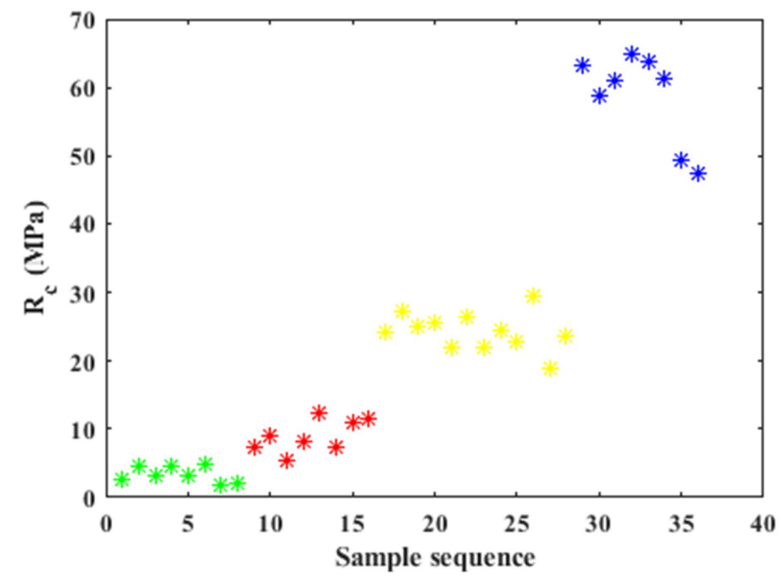

Figure 4. The classification result. Each color represents a rock.

\section{Discussion}

According to the stepwise regression analysis by MATLAB, we see that $W_{M}$ has the strong correlation with UCS of the rock shown in Figure 5. That means the rock is 
destroyed during the drilling process caused by the rotation of a bit. Hence, the UCS of rocks is greater than the shear and tensile strength. Apparently, the rotation mainly destroys the rock through the combined action of shearing and tension. For different strength of rock formations, to optimize the torque and thrust distribution ratio is an important research direction to improve the drilling efficiency.

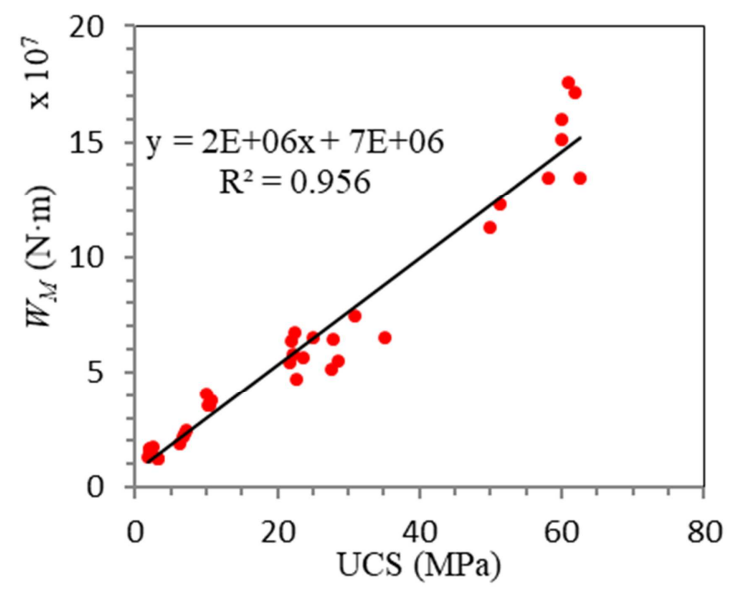

Figure 5. The relationship between UCS and WM.

The MSE has a significant correlation with UCS, and this conclusion has been verified by many scholars [9]. Compared with the traditional MSE model, the impact of drill reaming is considered in this paper. In addition, The comprehensive method proposed in this paper does not consider the geometry of the drill bit, while the model (DPUCS model) takes into account the geometry (Wang, et al. [14]). Therefore, the comprehensive prediction results are more accurate than the DP-UCS model, which shows that the geometry of the bit can be simplified in some cases. However, the enlargement of the diameter of the borehole and the friction between the side of the drill bit and the borehole wall are not considered in the paper, causing the prediction error.

Intelligent identification of rock formation, the trend of intelligent development, is of great significance to tunnel engineering, underground engineering, and mining engineering. In particular, to optimize the support parameters based on the MWD can better control the deformation of the surrounding rock in a roadway. Field experimental data acquisition for accurate identification of rock fissures will be the future research direction.

\section{Conclusions}

In this research work, it is found that the torque work has a high correlation with the rock strength. For different strength of rock formations, the optimization of the torque and thrust distribution ratio is an important research direction to improve the drilling efficiency. Next, the prediction result of the multiple linear regression model has the largest deviation, and the comprehensive method has the best prediction result. The experimental results show that the geometry of the drill bit can be ignored when using a comprehensive method.
Furthermore, based on the penetration rate, rotating speed, torque and thrust, the rock classification can be recognized by the silhouette coefficient and K-means clustering.

\section{Acknowledgements}

Appreciate to all co-authors for their valuable contribution during the preparation of this paper. We declare that we do not have any commercial or associative interest that represents a conflict of interest in connection with the work submitted.

\section{References}

[1] Tian, J., J. Li, W. Cheng, Z. Zhu., L. Yang., Y. Yang., T. Zhang. (2018). Working mechanism and rock-breaking characteristics of coring drill bit. Journal of Petroleum Science \& Engineering. 162: 348-357.

[2] Galdames, F. J., Perez, C. A., Estévez, P. A., Adams, M. (2017). Classification of rock lithology by laser range 3D and colour images. Estévez, et al. Rock Lithological Classification by Laser Range 3D and Color Images [J]. International Journal of Mineral Processing. 160, 47-57.

[3] Zhao, J., and Yu, j. (2017). Exploration on nonlinear geo-electrical structures to detect coal mine goafs using three-dimensional borehole resistivity imaging discrete approach, Journal of difference equations and applications. 23 (1-2), 312-321.

[4] Liu, C., X. Zheng, G. Wang, M. Xu, Z. Li. (2020). Research on drilling response characteristics of two-wing PDC bit. Sustainability, 12 (1), 406.

[5] Vardhan H, Adhikari G R, Raj M G. (2009). Estimating rock properties using sound levels produced during drilling. International Journal of Rock Mechanics \& Mining Sences. 46 (3): 604-612.

[6] Vardhan, H, Murthy C S N. (2007). An experimental investigation of jack hammer drill noise with special emphasis on drilling in rocks of different compressive strengths. Noise Control Engineering Journal. 55 (3): 282-293.

[7] Yasar, E., Ranjith, P. G., and Viete, D. R. (2011). An experimental investigation into the drilling and physicomechanical properties of a rock-like brittle material. Journal of Petroleum Science \& Engineering. 76 (3-4), 185-193.

[8] Rodgers, M., Mcvay, M., Horhota, D., et al. (2018). Assessment of rock strength from measuring while drilling shafts in Florida limestone. Canadian Geological Journal. 55, 1154-1167.

[9] Teale, R. (1965). The concept of specific energy in rock drilling. International Journal of Rock Mechanics \& Mining Sciences \& Geomechanics Abstracts. 2 (1), 57-73.

[10] Dupriest, F. E., W. L. Koederitz. Maximizing drill rates with real-time surveillance of mechanical specific energy. In: SPE/IADC Drilling Conference. Society of Petroleum Engineers 2005.

[11] Cherif, H., S. Bits. FEA modelled MSE/UCS values optimise PDC design for entire hole section. In: In at the North Africa Technical Conference and Exhibition Held in Cairo, Egypt, 20e22 February 2012. 
[12] Chen, X., D. Gao, B. Guo, Y. Feng. (2016). Real-time optimization of drilling parameters based on mechanical specific energy for rotating drilling with positive displacement motor in the hard formation. Journal of Natural Gas Science and Engineering. 35, 686-694.

[13] Al-Sudani, Jalal, A. (2017). Real-time monitoring of mechanical specific energy and bit wear using control engineering systems. Journal of Petroleum Science \& Engineering. 149, 171-182.

[14] Wang, Q., Q. Qin, S. Gao, S. Li, and H. Gao. (2018) Relationship between rock drilling parameters and rock uniaxial compressive strength based on energy analysis. Journal of China Coal Society. 43 (5), 1289-1295.

[15] Liu, W., Rostami, J., Keller, E. (2017). Application of new void detection algorithm for analysis of feed pressure and rotation pressure of roof bolters. International Journal of Mining Science and Technology. 27 (1): 77-81.

[16] Rostami, J., Kahraman, S., Naeimipour, A., Collins, C. (2015). Rock characterization while drilling and application of roof bolter drilling data for evaluation of ground conditions. Journal of Rock Mechanics and Geotechnical Engineering, 7 (3): 273-281.
[17] Liu, S., Y. Luo, and H. Jia. (2018). Energy response characteristics of rock interface under drilling of roof anchorage borehole in coal roadway. Journal of China University Mining Technology. 47 (1), 88-96.

[18] Song, Q., Jiang, H., Song, Q., Zhao, X., Wu, X. (2017). Combination of minimum enclosing balls classifier with SVM in coal-rock recognition. Plos One, 12 (9), e0184834.

[19] Liu, C., X. Zheng, A. Arif., and M. Xu. (2019). Measurement and analysis of penetration rate and vibration on a roof bolter for identification rock interface of roadway roof, Energy Sources, Part A: Recovery, Utilization, and Environmental Effects.

[20] Dong, S., Wang, Z., Zeng, L. (2016). Lithology identification using kernel Fisher discriminant analysis with well logs. Journal of Petroleum Science \& Engineering. 143, 95-102.

[21] Yahiaoui, M., Paris, J. Y., Delbé, K., Denape, J., Gerbaud, L., Dourfaye, A. (2016). Independent analyses of cutting and friction forces applied on a single polycrystalline diamond compact cutter. International Journal of Rock Mechanics \& Mining Sences. 85, 20-26. 